\title{
Single Oral Dose Toxicity Test of Kong-Jin-Dan, a Polyherbal Formula in ICR Mice
}

\author{
Mee-Yeon ParK ${ }^{1}$, Hae-Yun ChOI ${ }^{1}$, Jong-Dae Kiм ${ }^{1}$, Hyeung-Sik LeE ${ }^{\mathbf{2}}$ and Sae-Kwang Ku ${ }^{1}$ ** \\ ${ }^{1}$ College of Oriental Medicine, Daegu Haany University, Gyeongsan 712-715, Republic of Korea \\ ${ }^{2}$ Department of Herbal Biotechnology, Daegu Haany University, Gyeongsan, 712-715, Republic of Korea
}

(Received October 19, 2007; Accepted December 5, 2007)

\begin{abstract}
The object of this study was to evaluate the single dose toxicity of Kong-Jin-Dan (KJD), a polyherbal formula in male and female mice. KJD was administered to female and male ICR mice as an oral dose of 2000, 1000 and $500 \mathrm{mg} / \mathrm{kg}$ (body wt.) according to the recommendation of KFDA Guidelines. Animals were monitored for the mortality and changes in body weight, clinical signs and gross observation during 14 days after dosing, upon necropsy, organ weight and histopathology of 12 principle organs were examined. As results, we could not find any mortality, clinical signs, and changes in the body and organ weight except for increases of lymphoid organ weights in KJD-dosing groups. These increases of lymphoid organ weights considered that related to the immune modulate effect of KJD not toxicological signs. In addition, no KJD-treatment related abnormal gross findings and changes in histopathology of principle organs were detected except for some sporadic accidental findings. The results obtained in this study suggest that the KJD does not cause any toxicological signs. The LD $_{50}$ and approximate LD of KJD extracts in both female and male mice were considered as over $2000 \mathrm{mg} / \mathrm{kg}$.
\end{abstract}

Key words $\square$ Kong-Jin-Dan, single oral dose toxicity, mice, histopathology

\section{INTRODUCTION}

A polyherbal formula, Kong-Jin-Dan (KJD) is one of the most famous tonic agents, in Korean traditional folk medicine, and consisted of 4 herbs - Angelicae gigas radix, Ginseng steamed red, Corni fructus and Rehmanniae radix preparata, and 2 animal resources - antler and musk. These 6 agents were plastered using honey, and coated by gold plates. The hypolipemic and immune stimulatory effects of KJD are relatively well documented (Kim and Bae, 2001; Kim et al., 1999).

As increase of the concern in the functional food and well being in life, the demands and consumption of functional food originated form natural sources are increased (Lee et al., 2003). However, the toxicological aspects about these natural originfunctional foods has been neglected because of the reasons that they has been used as various purpose for long times. Therefore, it is considered that more detailed and systemic toxicological studies should be performed to control the abuse and potential toxicities even if they have been used as traditional

*Corresponding author

Tel: +82-53-819-1549, Fax: +82-53-819-1269

E-mail: gucci200@hanmail.net folk medicine. The toxicological studies about KJD also have been neglected and the reports dealing the toxicological aspects of KJD, even if the basic single dose toxicities in rodents are also seldom.

The objective of the present study, therefore, was to obtain the primary safety information about KJD, and to further clarity their safety for clinical use.

\section{MATERIALS AND METHODS}

\section{Animals and husbandry}

Each of twenty female and male ICR mice (6-wk old upon receipt, Charles River, Japan) was used after acclimatization for 14 days. Animals were allocated five per polycarbonate cage in a temperature $\left(20-25^{\circ} \mathrm{C}\right)$ and humidity $(45-50 \%)$ controlled room. Light : dark cycle was $12 \mathrm{hrs}: 12 \mathrm{hrs}$, and feed (Samyang, Korea) and water were supplied free to access. All animals were overnight fasted before dosing and terminal necropsy. Animals were marked by picric acid. The experimental protocols were conducted in accordance with internationally accepted principles for laboratory animal use and care as found in the Korea Food and Drug Administration (KFDA) guidelines. 


\section{Preparation and Administration of KJD}

KJD used in this study was purchased from Daegu Oriental Hospital of Daegu Hanny University (Daegu, Korea) as listed in Table I. Deep brown gold-coated plasters, KJD was stored in a refrigerator at $-20^{\circ} \mathrm{C}$ to protect from light and degeneration. KJD was well suspended upto $200 \mathrm{mg} / \mathrm{ml}$ concentration levels and appeared to be a deep brown homogenous suspension. The animals were grouped into 8 with 5 mice per group upon receipt. KJD have been used as folk medicine for long times, and no revealed toxicological data was available, the highest dosage level was selected as $2000 \mathrm{mg} / \mathrm{kg}$ according to the recommended by KFDA Guidelines (2005-60, 2005), the limited dosages and 1000 and $500 \mathrm{mg} / \mathrm{kg}$ was selected using common ratio 2. In addition, a vehicle control group was added as listed in Table II. Animals were given an oral dose of KJD prepared in water using a zonde attached to a syringe of $1 \mathrm{ml}$ after overnight fasting (about $18 \mathrm{hr}$, water was not restricted). Food and water were restricted further for about $3 \mathrm{hrs}$ after dosing.

\section{Abnormal behavior, clinical sign and body weight}

All abnormal clinical signs and behaviors were recorded before and after dosing at least twice a day based on the functional observational battery test (Irwin, 1968; Dourish, 1987). Body weights were measured on the day of dosing (Day 0) prior to treatment, 1, 2, 7, 13 and 14 days after dosing. In addition, to reduce the differences from individual body weight differences of animals at treatment, body weight gains during Day $0 \sim$ Day 7 , Day $7 \sim$ Day 13 and Day $0 \sim$ Day 13 was also calculated based on measured body weight at each point.

\section{Necropsy}

Necropsy was done on the animals found dead during the experiment and all animals were subjected to terminal necropsy at the end of experiment at Day 14 after overnight fasting
Table II. Experimental design used in this study

\begin{tabular}{cccc}
\hline Group & Sex & No. of animals & $\begin{array}{c}\text { Total Dose }(\mathrm{mg} / \mathrm{kg}) \\
\text { of Kong-Jin-Dan }\end{array}$ \\
\hline G0M* & Male & 5 & 0 \\
G1M & Male & 5 & 2000 \\
G2M & Male & 5 & 1000 \\
G3M & Male & 5 & 500 \\
G0F* & Female & 5 & 0 \\
G1F & Female & 5 & 2000 \\
G2F & Female & 5 & 1000 \\
G3F & Female & 5 & 500 \\
\hline
\end{tabular}

*Vehicle control; distilled water $10 \mathrm{ml} / \mathrm{kg}$ as vehicle in this study; All test articles in vehicle were once orally dosed.

(about 18hr, water was not restricted). Animals were euthanized by carbon dioxide and gross necropsy was performed.

\section{Organ weight measurements and sampling}

The absolute organ weight was measured and then relative organ weight (\% for body weight) was calculated. The following organs were collected for histopathological observation.

Measured and sampled organs: lung, heart, thymus, left kidney, left adrenal gland, spleen, left testis or ovary, liver, splenic lobe of pancreas, brain, left epididymis or total uterus and left popliteal lymph node.

\section{Histopathology}

Samples were fixed in $10 \%$ neutral buffered formalin. After $18 \mathrm{hrs}$ of fixation, paraffin embedding was conducted and $4 \mu \mathrm{m}$ sections were prepared by routine histological methods. Representative sections of each specified organs were stained with hematoxylin-eosin for light microscopical examination.

\section{Statistical analyses}

Multiple comparison tests for different dose groups were

Table I. Composition of Kong-Jin-Dan Used in This Study

\begin{tabular}{llc}
\hline \multicolumn{1}{c}{ Herbs } & \multicolumn{1}{c}{ Scientific Names } & Amounts (g/1 pill) \\
\hline Antler (Cornus cervi parvum) & Cervus elaphus Linne & 0.683 \\
Angelicae gigantis radix & Angelica gigas Nakai & 0.683 \\
Ginseng steamed red & Panax ginseng CA Mey. & 0.683 \\
Corni fructus & Cornus officinalis Sieb. Et Zucc & 0.683 \\
Rehmanniae radix preparata & Rehmannia glutinosa (Gaertner) Liboschitz & 0.683 \\
Musk & Moschus moschiferus Linne & 0.122 \\
Honey & Apis indica Radoszkowski & 2.506 \\
Gold plate & & 0.006 \\
Total & 8 types & 6.050
\end{tabular}

Kong-Jin-Dan used in this study was purchased from Daegu Oriental Hospital of Daegu Hanny University (Daegu, Korea) 
conducted. Variance homogeneity was examined using the Levene test. If the Levene test indicated no significant deviations from variance homogeneity, the obtain data were analyzed by one way ANOVA test followed by Tukey HSD test to determine which pairs of group comparison were significantly different. In case of significant deviations from variance homogeneity were observed at Levene test, a non-parametric comparison test, the Mann-Whitney U-Wilcoxon Rank Sum W test was conducted to determine the specific pairs of group comparison, which are significantly different. $\mathrm{LD}_{50}$ and $95 \%$ confidence limits were calculated by Probit method. Statistical analyses were conducted using SPSS for Windows (Release 6.1.3., SPSS Inc., USA) and a $p$-value of less than 0.05 was considered to be a significant difference. In addition, degree of clinical signs, gross and histopathological findings were subdivided into 3 degrees: $3+$ Severe, $2+$ moderate, $1+$ slight.

\section{RESULTS}

\section{Mortality rate}

No sudden mortality was detected in all dose levels tested. All animals $(5 / 5 ; 100 \%)$ survived in all dose levels tested including vehicle control.

\section{Abnormal clinical signs detected}

In this study, no KJD treatment related abnormal clinical signs were observed during observation periods regardless of male and female mice.

\section{Changes of body weights}

No significant changes in body weight were detected compared to that of vehicle control in all dose levels tested (Table III).

Table III. Body weight gains in female and male mice after once orally dose of Kong-Jin-Dan

\begin{tabular}{ccccc}
\hline \multirow{2}{*}{ Group } & \multicolumn{3}{c}{ Interval } \\
\cline { 3 - 5 } MALE & G0M & $5.64 \pm 1.62$ & $1.78 \pm 1.80$ & $7.42 \pm 1.74$ \\
& G1M & $5.72 \pm 0.99$ & $1.80 \pm 0.80$ & $7.52 \pm 1.36$ \\
& G2M & $5.32 \pm 0.94$ & $1.30 \pm 1.75$ & $6.69 \pm 1.14$ \\
& G3M & $5.32 \pm 1.17$ & $1.38 \pm 1.33$ & $6.70 \pm 1.50$ \\
FEMALE & G0F & $4.34 \pm 1.72$ & $1.60 \pm 2.45$ & $5.94 \pm 1.06$ \\
& G1F & $5.30 \pm 1.54$ & $1.64 \pm 2.19$ & $6.94 \pm 1.05$ \\
& G2F & $3.00 \pm 1.60$ & $1.14 \pm 0.63$ & $4.14 \pm 1.44$ \\
& G3F & $4.60 \pm 1.75$ & $1.16 \pm 0.93$ & $5.76 \pm 2.11$ \\
\hline
\end{tabular}

Values are expressed as mean \pm S. D., g $(n=5)$; ${ }^{a}$ Day of dosing.

\section{Changes of organ weights}

No significant changes in the absolute and relative weight of 12 principle organs were observed in all dose groups compared to that of vehicle control except for lymphatic organ weights. In KJD 2000 and $1000 \mathrm{mg} / \mathrm{kg}$-treated male and female mice showed significantly $(p<0.01$ or $p<0.05)$ increases of absolute and relative spleen and popliteal lymph node weights as compared with vehicle control, respectively. In addition, $2000 \mathrm{mg} /$ $\mathrm{kg}$ of KJD-treated female mice also showed significantly $(\mathrm{p}<$ 0.05 ) increase of absolute thymus weight, and significant $(p<0.01)$ increase of relative heart weight was detected in KJD $1000 \mathrm{mg} / \mathrm{kg}$-treated male mice as compared with vehicle control. In $500 \mathrm{mg} / \mathrm{kg}$ of KJD-treated females, significantly $(\mathrm{p}<$ 0.05 ) increases of absolute and relative popliteal lymph node weights and relative thymus weights were detected as compared with vehicle control, respectively (Table IV, V).

\section{Necropsy findings}

No significant changes in the gross findings of 12 principle organs were observed in all dosing groups compared to that of vehicle control except for increased incidences of the hypertrophy of spleen encounted in KJD treated male and female groups. Some animals showed sporadic accidental findings such as congestion spots of lung, atrophy of thymus, cyst of kidney, spleen atrophy, liver atypical white foci and edematous changes of uterus (Table VI).

\section{Histopathological findings}

No significant histopathological findings were observed in 12 principle organs of all dose groups tested compared to that of vehicle control except for hypertrophy of lung alveolus wall with hemorrhage (Fig. 1), focal necrotic foci and inflammatory cell infiltration in liver (Fig. 2), cyst in kidney (Fig. 3), depletion of lymphoid cells in red pulps of spleen (Fig. 4), and desquamation of mucosa in uterus (Fig. 5) (Table VII).

\section{DISCUSSION}

In the present study, we investigated the single oral dose toxicity of KJD, a polyherbal formula to mice as a part of the safety test. In order to observe $50 \%$ lethal dose $\left(\mathrm{LD}_{50}\right)$ and approximate lethal dosage (LD), test substances were administered orally to female and male ICR mice at dose levels of 2000,1000 and $500 \mathrm{mg} / \mathrm{kg}$. However, we could not find any mortality, clinical signs, and changes in the body and organ weight except for increases of lymphoid organ weights in KJD- 

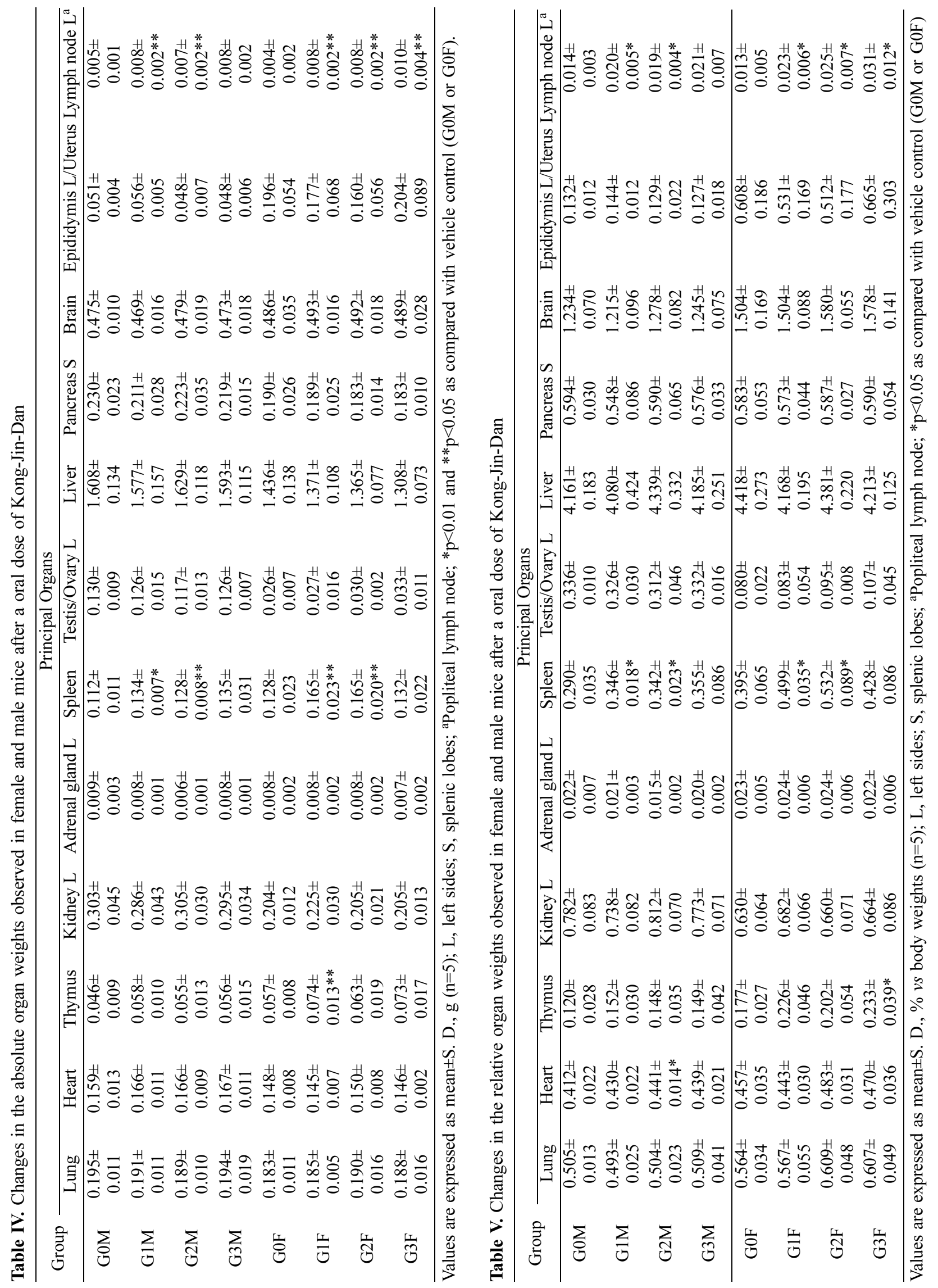
Table VI. Necropsy findings in female and male mice after once orally dose of Kong-Jin-Dan

\begin{tabular}{|c|c|c|c|c|c|c|c|c|}
\hline \multirow{2}{*}{ Group } & \multicolumn{5}{|c|}{$\begin{array}{c}\text { MALE } \\
\end{array}$} & \multicolumn{3}{|c|}{ FEMALE } \\
\hline & $\overline{\mathrm{G} 0 \mathrm{M}}$ & $\overline{\mathrm{G} 1 \mathrm{M}}$ & $\overline{\mathrm{G} 2 \mathrm{M}}$ & $\overline{\mathrm{G} 3 \mathrm{M}}$ & G0F & G1F & $\mathrm{G} 2 \mathrm{~F}$ & G3F \\
\hline $\begin{array}{l}\text { Lung } \\
\end{array}$ & & & & & & & & \\
\hline Congestion & $2 / 5$ & $1 / 5$ & $1 / 5$ & $2 / 5$ & $1 / 5$ & $1 / 5$ & $1 / 5$ & $0 / 5$ \\
\hline Thymus & & & & & & & & \\
\hline Atrophy & $2 / 5$ & $0 / 5$ & $0 / 5$ & $0 / 5$ & $0 / 5$ & $0 / 5$ & $0 / 5$ & $0 / 5$ \\
\hline Kidney & & & & & & & & \\
\hline Cyst & $0 / 5$ & $1 / 5$ & $0 / 5$ & $0 / 5$ & $0 / 5$ & $0 / 5$ & $0 / 5$ & $0 / 5$ \\
\hline Spleen & & & & & & & & \\
\hline Atrophy & $1 / 5$ & $0 / 5$ & $0 / 5$ & $0 / 5$ & $1 / 5$ & $0 / 5$ & $0 / 5$ & $0 / 5$ \\
\hline Hypertrophy & $0 / 5$ & $1 / 5$ & $2 / 5$ & $2 / 5$ & $0 / 5$ & $2 / 5$ & $2 / 5$ & $1 / 5$ \\
\hline Liver & & & & & & & & \\
\hline Atypical foci & $0 / 5$ & $0 / 5$ & $1 / 5$ & $0 / 5$ & $0 / 5$ & $0 / 5$ & $0 / 5$ & $0 / 5$ \\
\hline Uterus & & & & & & & & \\
\hline Edematous changes & & & & & $2 / 5$ & $2 / 5$ & $1 / 5$ & $2 / 5$ \\
\hline
\end{tabular}

Values are expressed as observed animals/total observed animals $(\mathrm{n}=5)$

Table VII. Histopathological findings in female and male mice after once orally dose of Kong-Jin-Dan

\begin{tabular}{llllllllll}
\hline \multirow{2}{*}{ Group } & \multicolumn{4}{c}{ MALE } & \multicolumn{5}{c}{ FEMALE } \\
\cline { 2 - 8 } & G0M G1M G2M G3M G0F & G1F & G2F & G3F \\
\hline $\begin{array}{c}\text { Lung } \\
\text { Congestion }\end{array}$ & $2 / 5$ & $1 / 5$ & $1 / 5$ & $2 / 5$ & $2 / 5$ & $1 / 5$ & $1 / 5$ & $0 / 5$ \\
$\begin{array}{c}\text { Kidney } \\
\text { Cyst }\end{array}$ & $0 / 5$ & $1 / 5$ & $0 / 5$ & $0 / 5$ & $0 / 5$ & $0 / 5$ & $0 / 5$ & $0 / 5$ \\
$\begin{array}{c}\text { Spleen } \\
\quad L^{1)}\end{array}$ & $1 / 5$ & $0 / 5$ & $0 / 5$ & $0 / 5$ & $0 / 5$ & $0 / 5$ & $0 / 5$ & $0 / 5$ \\
$\begin{array}{c}\text { Liver } \\
\quad \text { IF-FN }\end{array}$ & $2 / 5$ & $0 / 5$ & $1 / 5$ & $1 / 5$ & $1 / 5$ & $1 / 5$ & $1 / 5$ & $2 / 5$ \\
$\begin{array}{c}\text { Uterus } \\
\text { DM }^{3)}\end{array}$ & & & & & $3 / 5$ & $2 / 5$ & $0 / 5$ & $2 / 5$ \\
\hline
\end{tabular}

Values are expressed as observed animals/total observed animals $(\mathrm{n}=5) ;{ }^{1}$ DL, depletion of lymphoid cells in red pulps; ${ }^{2} \mathrm{IF}-\mathrm{FN}$, focal necrosis with inflammatory cell infiltration; ${ }^{3} \mathrm{DM}$, desquamation of mucosa.

dosing groups. In addition, no KJD-treatment related abnormal gross findings and changes in histopathology of principle organs were detected except for some sporadic accidental findings

No KJD extracts related histopathological changes were detected in all three lymphatic organs; lymph nodes, spleen and thymus observed in the present study, although the hypertrophy of spleen in gross findings and increases of lymphatic organ weights. The increases in the weights of lymphatic organs were frequently observed after treatment of immune enhancers with (Klein et al., 1987; Iqbal et al., 2001) with hypertrophy and hyperplasia of lymphoid cells (Lee et al., 2005). These changes detected in the present study, therefore considered that related to the immune modulate effect of KJD not toxicological signs.

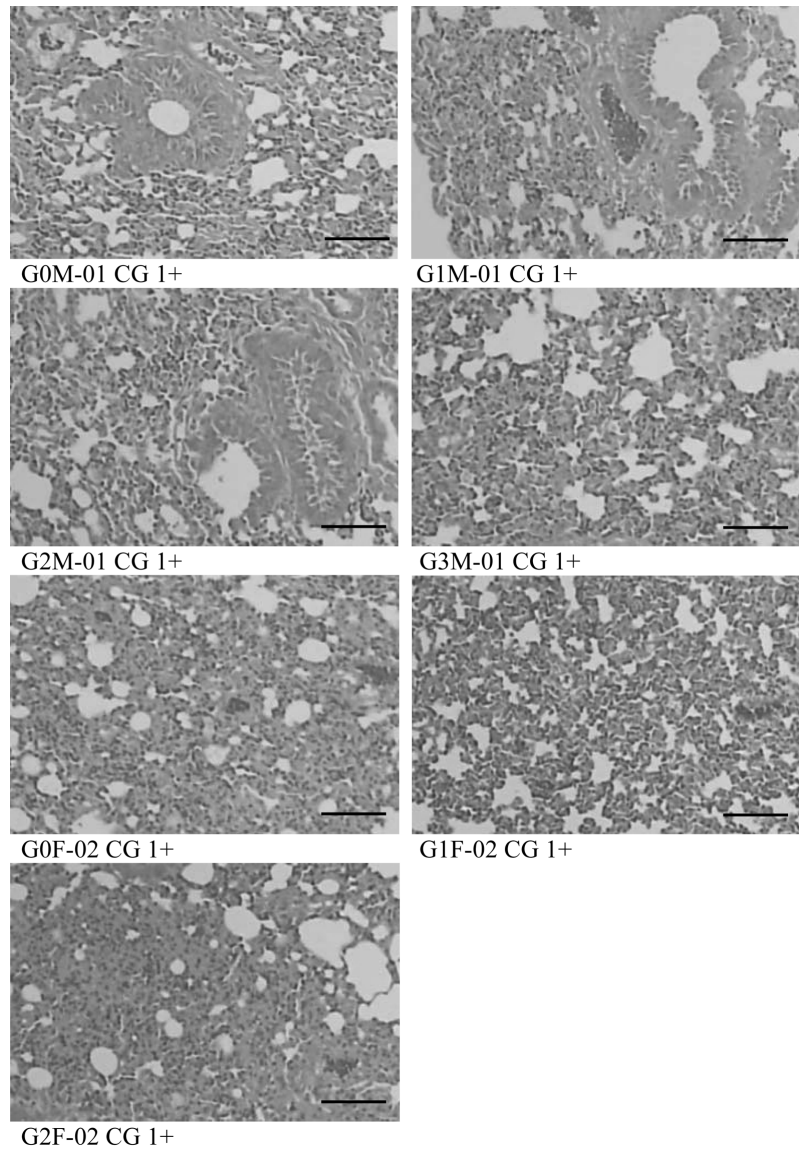

Fig. 1. Histopathological changes detected in the lung. Note that hypertrophy of alveolus as congestion with hemorrhage (CG) were randomly detected and dispersed throughout the all tested groups including vehicle control. All Hematoxylin \& Eosin stain; Scale bars $=8 \mu \mathrm{m}$

The immune enhancer effects of KJD were already reported (Kim et al., 1999). Significant increase of relative heart weight restricted to KJD $1000 \mathrm{mg} / \mathrm{kg}$-treated male group was considered as accidental findings, and they were not considered as KJD-treatment related abnormal sign because they did not showed any dose-dependency and no meaningful changes on the heart at histopathological and gross observations in the present study.

In KFDA Guidelines (2005-60, 2005), the recommended highest dose of test materials is $2000 \mathrm{mg} / \mathrm{kg}$ or the maximum solubility in a volume below $20 \mathrm{ml} / \mathrm{kg}$ for studies of single toxicity in mice. In the present study, the highest dose of KJD was selected as $2000 \mathrm{mg} / \mathrm{kg}$ because KJD have been used as traditional medicine for long times and no revealed toxicological data was available.

Congestion spots of lung, atrophy of thymus, cyst of kidney, 

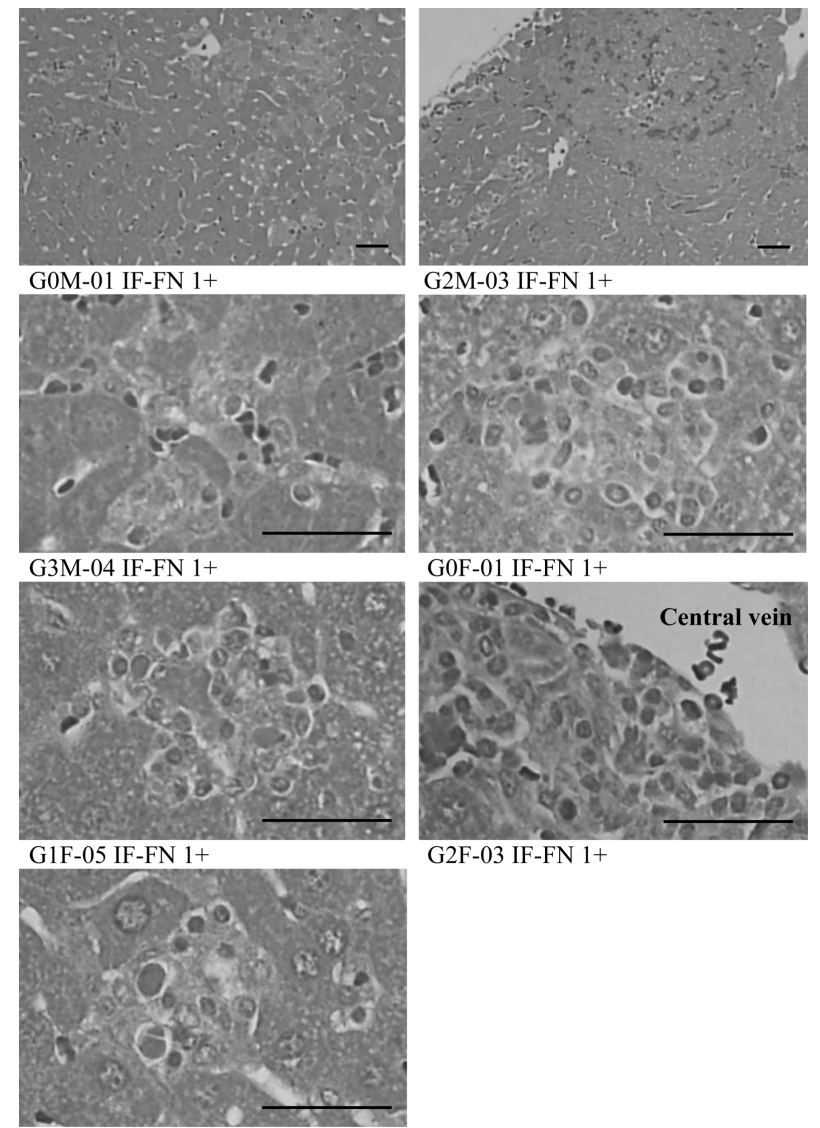

G0F-01 IF-FN 1+

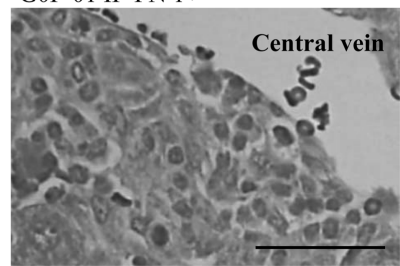

G2F-03 IF-FN 1+

G3F-04 IF-FN 1+

Fig. 2. Histopathological changes detected in the liver. Note that focal necrotic foci with inflammatory cell infiltration (IFFN) were randomly observed including vehicle controls as accidental findings. All Hematoxylin \& Eosin stain; Scale bars $=40 \mu \mathrm{m}$.

spleen atrophy, liver atypical white foci and edematous changes of uterus detected as gross findings, and hypertrophy of lung alveolus wall with hemorrhage, focal necrotic foci and inflammatory cell infiltration in liver, cyst in kidney, depletion of lymphoid cells in red pulps of spleen, and desquamation of mucosa

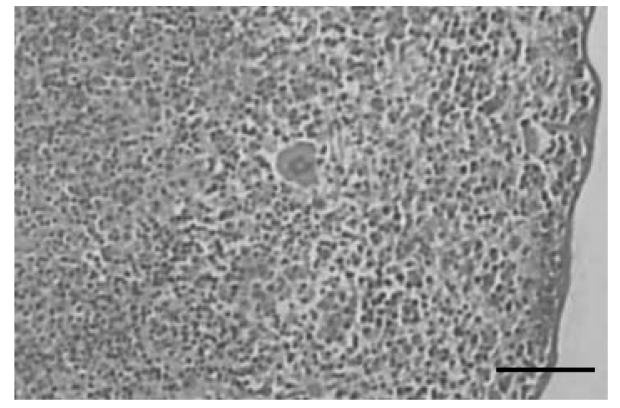

\section{G2M-05 Cyst 1+}

Fig. 4. Histopathological changes detected in the spleen. Note that depletion of lymphoid cells (DL) in red pulps was detected only one animal of female vehicle control as accidental findings. All Hematoxylin \& Eosin stain; Scale bars $=80 \mu \mathrm{m}$.
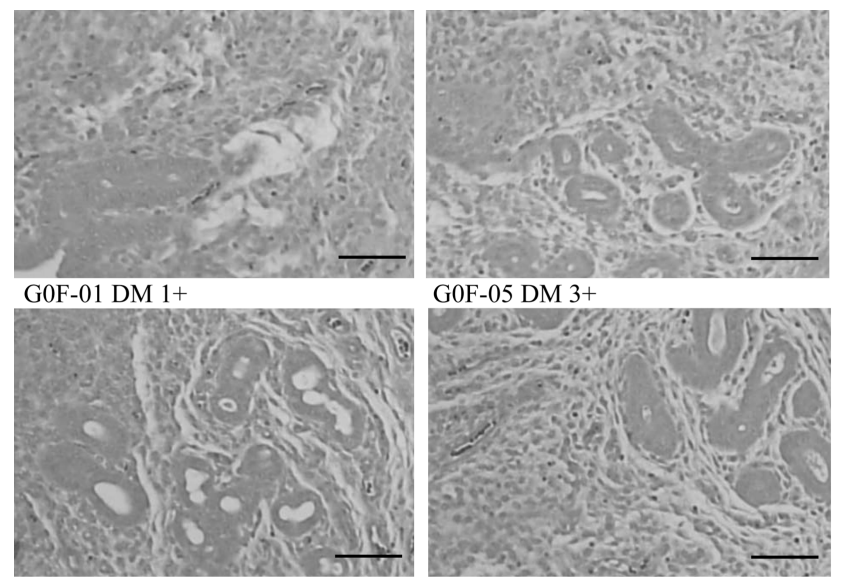
G0F-05 DM 3+

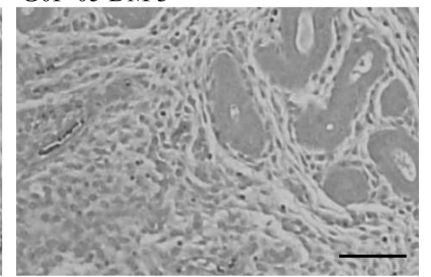

G3F-05 DM 3+

Fig. 5. Histopathological changes detected in the uterus. Note that desquamation of mucosa (DM) in uterus were randomly detected and dispersed throughout the all tested groups including vehicle control. All Hematoxylin \& Eosin stain; Scale bars $=80 \mu \mathrm{m}$.

in uterus detected as histopathological findings were also considered as accidental findings, and they were not considered as

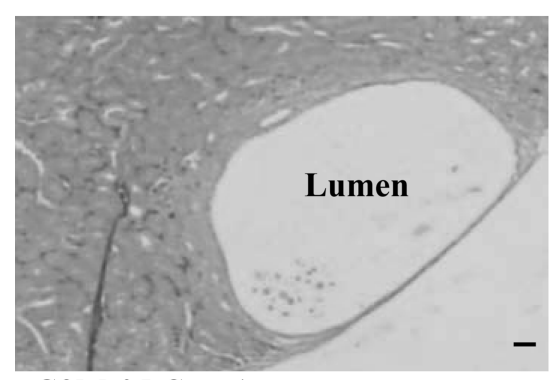

G2M-05 Cyst 1+

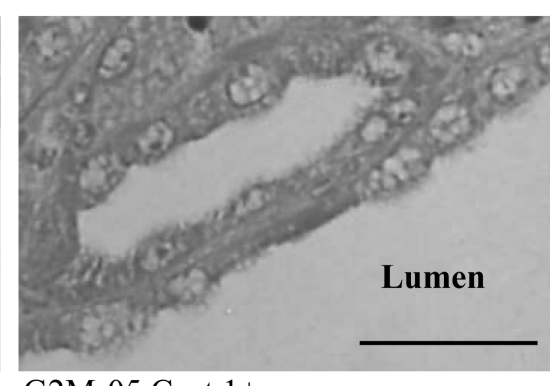

G2M-05 Cyst 1+

Fig. 3. Histopathological changes detected in the kidney. Note that cyst was detected only one animal of KJD $1000 \mathrm{mg} / \mathrm{kg}$-treated male as one of accidental findings. All Hematoxylin \& Eosin stain; Scale bars $=40 \mu \mathrm{m}$. 
KJD-treatment related abnormal gross or histopathological findings because they were restricted in some individual animals and most of the case, also observed in vehicle control. In addition, most of them were rarely observed in normal mice (Lee et al., 2005; Lee et al., 2006). Liver atypical white foci detected at gross observations in the present study were revealed as relatively broaden focal necrotic foci with inflammatory cell infiltration in liver at histopathological observations.

Hodge and Sterner (1949) classify as non toxic materials for those with $\mathrm{LD}_{50}$ of $5000 \sim 15000 \mathrm{mg} / \mathrm{kg}$ and those with $\mathrm{LD}_{50}$ of $500 \sim 5000 \mathrm{mg} / \mathrm{kg}$ as relatively low toxic (Class III) in US Environmental Protection Agency (OPPTS 870.100; 1998). However, recent guideline by Korean Food and Drug Administration $(2005-60,2005)$ recommended that the highest oral dose of test materials should be $2000 \mathrm{mg} / \mathrm{kg}$. The $\mathrm{LD}_{50}$ and approximate $\mathrm{LD}$ in mice after single oral dose of KJD were detected over $2000 \mathrm{mg} / \mathrm{kg}$ in both male and female in the present study. Therefore, oral administration of KJD caused no serious toxic effect to the male and female mice upto $2000 \mathrm{mg} / \mathrm{kg}$ - the highest dosage tested in this study and is likely to be safe in humans.

\section{REFERENCES}

Dourish, C.T. (1987). Effects of drugs on spontaneous motor activity. In Experimental Psychopharmacology (A.J. Greenshaw and C.T. Dourish, Ed.), pp. 325-334. Humana Press, Clifton.

Hodge, H.C. and Sterner, J.H. (1949). Tabulation of toxicity classes. Am. Ind. Hyg. Q. 10, 93.

Iqbal, M.P., Sultana, F., Mehboobali, N. and Pervez, S. (2001). Folinic acid protects against suppression of growth by methotrexate in mice. Biopharm. Drug Dispos. 22, 169-178.

Irwin, S. (1968). Comprehensive observational assessment: Ia. A systemic, quantitative procedure for assessing the behavioral and physiological state of the mouse. Psychopharmacology 13, 222-257.

Kim, Y.H. and Bae, M.J. (2001). The effect of Kong Jin Dan on the lipid metabolism in rats fed high fat-diet. J. East-West Med. 14, 61-78.

Kim, Y.S., Lee, J.D., Kim, C.H., Choi, D.Y., Park, D.S., Nam, S.S. and Kang, S.K. (1999). The Effect of Kongjindan Aquaacupuncture on the $\mathrm{CD} 4+\mathrm{T}$ cell count at al. in rats were administered with MTX. J. Korean Acup. Moxi. Soc. 16, 179202.

Klein, H.O., Kreysch, H.G., Coerper, C., Voigt, P. and Ruff, I. (1987). Preclinical and early clinical trial with mafosfamide as immune modulator. Methods Find Exp. Clin. Pharmacol. 9, 627-640.

Korea Food and Drug Administration (2005): Testing Guidelines for Safety Evaluation of Drugs (Notification No. 2005-60, issued by the Korea Food and Drug Administration on October 21, 2005).

Lee, H.S., Lee I.G. and Ku S.K. (2006). Single oral dose toxicity study of water extracts of Picrorrhiza Rhizoma in mice. J. Toxicol. Pub. Health 22, 117-126.

Lee, J.E., Kim, H.J., Choi, E.K, Chai, H.Y., Yun, Y.W., Kim, D.J., Nam, S.Y., Lee, B.J., Ahn, B.W., Kang, H.G. and Kim, Y.B. (2003). Four-week repeated-dose toxicity study on Pinellia Extract. Korean J. Lab. Anim. Sci. 19, 127-141.

Lee, J.H, Yang, K.J., Shin, H.D., Park, B.R., Son, C.W., Jang, H.J., Park, D.C., Lee, H.S. and Ku, S.K. (2005). Single subcutaneous dose toxicity of Polycan ${ }^{\circledR}$, a $\beta$-glucan originated from Aureobasidium in mice. Lab. Anim. Res. 21, 299-305.

US Environmental Protection Agency (1998). Health Effects Test Guidelines OPPTS 870.100, Acute Toxicity Testing Background. US EPA August, Washington, USA. 